\title{
IMPACT BEHAVIOUR OF SPOT-WELDED THIN-WALLED FRUSTA
}

\author{
Maria KOTEŁKO*, Artur MOŁDAWA* \\ *Faculty of Mechanical Engineering, Department of Strength of Materials, Łódź University of Technology, \\ ul. Stefanowskiego 1/15, 90-924 Łódź, Poland \\ maria.kotelko@p.lodz.pl, artur.moldawa@dokt.p.lodz.pl
}

received 19 October 2015, revised 27 November 2016, accepted 30 November 2016

\begin{abstract}
In the paper the dynamic response of thin-walled, spot-welded prismatic frusta subjected to axial impact load is investigated. The parametric study into the influence of several parameters on the energy absorption capability, expressed by some crashworthiness indicators is performed, using Finite Element simulations. FE model is validated by experimental results of quasi-static and dynamic (impact) tests. Results of initial study concerning influence of spot welds are presented. Some conclusions are derived from the parametric study into the influence of frustum angle and wall thickness upon the energy absorption capability.
\end{abstract}

Key words: Thin-Walled Structures, Frusta, Impact, Energy Absorption

\section{INTRODUCTION}

Dynamic response of structures in the plastic range is a significant problem in the case of energy absorbers. Such a structural member converts totally or partially the kinetic energy into another form of energy. One of the possible design solutions is the conversion of the kinetic energy of impact into the energy of plastic deformation of a thin-walled metallic structural member. There are numerous types of energy absorbers of that kind cited in the literature (Alghamidi, 2001).

Thin-walled metal tubes are widely used as energy absorption systems in automotive industry due to their high energy absorption capability, easy to fabricate, relatively low price and sustainability at collapse.

A designer of any impact attenuation device must meet two main requirements. The initial collapse load (peak load) must not be too high in order to avoid unacceptably high impact velocities of the vehicle. On the other extreme, the main requirement is a possibly highest energy dissipation capacity, which may not be achieved if the collapse load of the impact device is too low. Thus, maximizing energy absorption and minimizing peak to mean force ratio by seeking for the optimal design of these components are of great significance. Many efforts have been made so far by several researchers to reduce the peak load at initial stage of the crushing process and simultaneously to increase energy absorption capacity in metal tubes, acting as energy absorbers.

One of the solutions are flaws or dents acting as triggers. A trigger may induce the most desirable crushing (collapse) mode, leading to higher energy absorption and mean to peak crushing force ratio. Ferdynus (Ferdynus and Kotełko, 2015) performed the static analysis of axially compressed square section tube with dents in the corners. A parametric study into an optimal dents situation and geometry with respect to the energy absorption capacity of tubes with dents subjected to axial impact was performed by the same author in Abbasi et al., (2015).
In last few years research was carried out into another solution, namely an application of multi-cornered thin-walled tubes as energy absorbing members. Abbasi et al. (2015) investigated crushing behavior and energy absorption of hexagonal, octagonal and 12-edge thin-walled columns. Reddy et al. (2015) continued to analyze the similar problem for 12-edge columns of different geometry. Ali et al. (2015) analyzed axial crushing of pentagonal and cross-shape thin-walled tubes. Another solution, bitubal energy absorber was investigated experimentally under quasi-static load by Sharifi et al. (2015).

An alternative solution are compressed thin-walled frusta (truncated circular cones or prisms) (Alghamdi, 2001), currently used as impact attenuation members in car structures, mainly due to the reduction of the peak crushing load in relation to parallelepiped. There are few published results, concerning this type of energy absorbing members. Very recently, Sarkabiri et al. (2015) published the results of multi-objective crashworthiness optimization of thin-walled conical groove tubes filled with polyurerthane foam. They stated, that the conical angle reduces the peak crushing force, however it reduces also the absorbed energy.

\section{SUBJECT AND OBJECTIVES OF THE ANALYSIS}

The subject of investigation was a thin-walled prismatic frustum on square foundation of constant edge length $a=90 \mathrm{~mm}$ and height $h=160 \mathrm{~mm}$, shown in Fig. 1, subjected to axial, dynamic (impact) compressive load.

The first objective of the research was the investigation into an influence of spot welds on the crushing behavior of the frustum. Particularly, situation, number of spot welds and their diameter were taken into account in the analysis.

The main objective was the parametric study into the energy absorption capacity, ultimate load and mean crushing load of thin-walled prismatic frusta subjected to axial impact compressive 
force. Particularly, the influence of the angle of inclination of the frustum wall was examined.

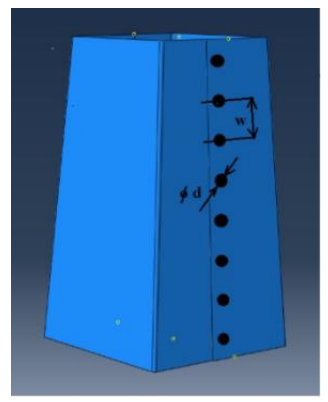

Fig. 1. Thin-walled spot welded frustum

There are several crashworthiness indicators (Jones, 2003) used to evaluate the crashworthiness of the energy absorbing structure (energy absorber). In the present analysis the following indicators are applied:

- energy absorption (EA);

- mean crushing force (MCF);

- crash load efficiency (CLE).

The typical crushing force - displacement curve for a thinwalled member subjected to axial impact is shown in Fig. 2.

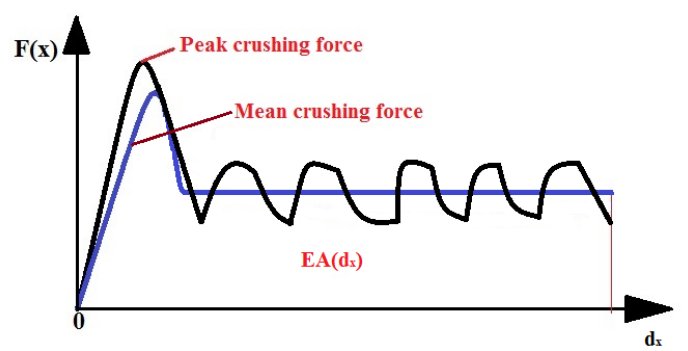

Fig. 2. Exemplary force - displacement curve for thin-walled member under axial impact

The energy absorbtion (EA) is calculated as an following integral:

$E A\left(d_{x}\right)=\int_{0}^{d_{x}} F(x) d x$

where $d_{x}$ is a crushing distance (see Fig. 2). The mean crushing force (MCF) for a given crushing deformation $\mathrm{d}_{\mathrm{x}}$ is calculated as:

$M C F=\frac{E A\left(d_{x}\right)}{d_{x}}$

Crash load efficiency is a mean crushing force (MCF) to peak crushing force (PCF - see Fig.2) ratio:

$C L E=\frac{M C F}{P C F} \cdot 100 \%$

In the parametric study the above mentioned indicators were determined in terms of the angle of inclination of the frustum and its wall thickness.

\section{FINITE ELEMENT MODEL}

Finite element calculations were carried out using commercial code Abaqus (Finite Element calculations carried out in Abaqus by CYFRONET AGH. MNiSW/IBM_BC_HS21/PŁódzka/013/2013) and explicit dynamic analysis (Dassault Systems, 2013). An FE model of the column was created using 4-node shell elements S4R. A column model was situated between two rigid elements R3D4 (Fig. 3). Between upper and lower rigid elements and the column Tie links were applied. In the analysis the residual stresses coming from forming process of the metal sheet were taken into account. FE simulation of sheet folding process was performed. Then, the equivalent residua stresses obtained in this simulation were used as initial conditions in the explicit analysis of impact behaviour. a)

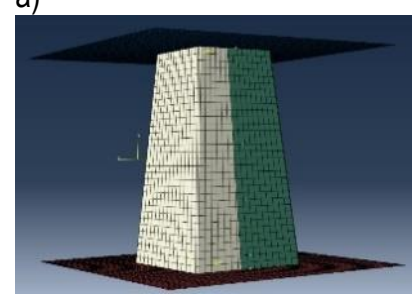

b)

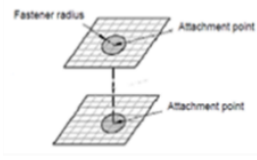

Fig. 3. FE model: a)- frustum model, b)- spot weld model

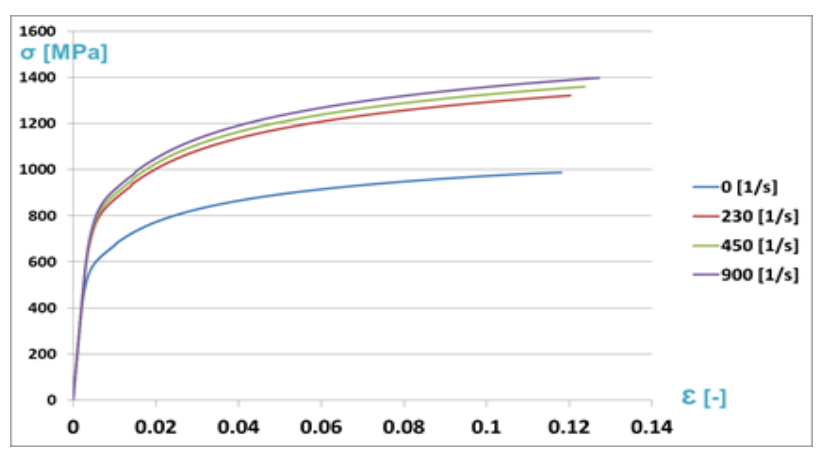

Fig. 4. Material characteristics for varying strain rates

The spot welds were modelled using the rigid beam elements (Fig. 3b), situateted between two overlapping shell elements. Using the FASTENER elements nodes in the area of the spot weld were connected.

$\bar{\sigma}\left(\dot{\bar{\varepsilon}}_{p l}, \bar{\varepsilon}_{p l}\right)=\sigma_{0}\left(\bar{\varepsilon}_{p l}\right) \cdot R\left(\dot{\bar{\varepsilon}}_{p l}\right)$

where: $\sigma_{0}$ - static (initial) yield stress, $\dot{\bar{\varepsilon}}_{p l}-$ equivalent plastic strain rate, $R$ - yield stress ratio, $\bar{\varepsilon}_{p l}$ - equivalent plastic strain.

The rate-dependent elasto-plastic material model, taking into account the strain rate and strain hardening has been applied, the constitutive relation of which is given in (4). Equivalent stress and equivalent plastic strain were calculated using Huber-Mises yield criterion. The coefficient $R$ was determined for subsequent equivalent plastic strain rates from tensile and compressive test curves (Fig.4) corresponding to subsequent strain rates. First, material parameters were determined in tensile and compressive static tests, in order to obtain a basic stress-strain curve. Then, on the basis of the data from literature (Kaczyński and Rusiński, 2014), curves corresponding to subsequent strain rates were determined. Afterwards, calibration of the material model was carried out using Abaqus program (Dassault Systems, 2013).

Calculations were carried out for high quality steel Dual Phase DP 800, with main strength parameters: yield stress $\sigma_{0}=590$ $\mathrm{MPa}$,

Young modulus $E=210 \mathrm{GPa}$. From the same material columns (frusta) for experimental tests were fabricated. 


\section{EXPERIMENTAL VALIDATION OF FE RESULTS}

Experimental verification of FE simulations was carried out both for quasi-static and dynamic (impact) load. Quasi-static tests were performed on the testing machine Instron, with the load velocity $v_{0}=600 \mathrm{~mm} / \mathrm{min}$. The comparative load-shortening diagram and failure modes obtained theoretically and experimentally are shown in Fig. 5. The agreement of FE simulation results and experimental results of quasi-static tests was satisfactory.

Preliminary impact tests were performed on the drop-hammer rig, described in detailes in Kotetko et al., (2014). The comparative load-time diagram for the parallelepiped is shown in Fig. 6. The agreement in the case of impact load was also satisfactory, although the discrepancy of experimental and theoretical results was larger in the final stage of failure, which was partially caused by additional vibrations measured by the accelerometer (Kotełko et al., 2014).

a)

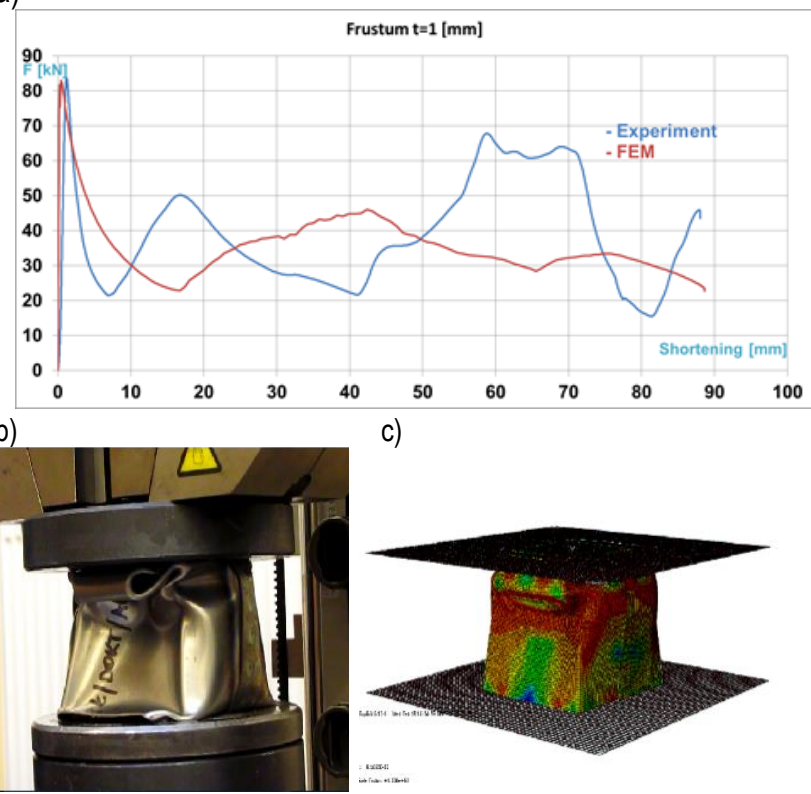

Fig. 5: a) Load-shortening comparative diagram for quasi-dynamic load: frustum angle $\left.\alpha=5^{\circ}, t=1 \mathrm{~mm}, b\right)$ failure mode (experiment), c) - failure mode (FE simulation)

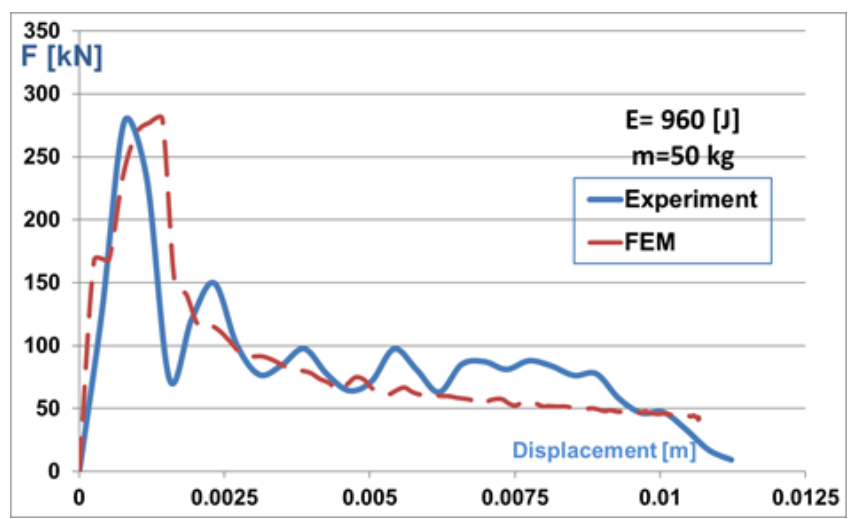

Fig. 6. Load-time comparative diagram for dynamic load for parallelepiped $\left(\alpha=0^{\circ}\right), t=1, v_{0}=6.19 \mathrm{~m} / \mathrm{s}$

\section{RESULTS OF PARAMETRIC STUDY}

\subsection{Influence of spot welds on the frusta crushing behavoiur}

There are very few fragmented information about an influence of spot welding on the crushing behavior of thin-walled members subjected to axial impact (Rusiński et al., 2004).

In the present study the influence of the diameter and number of spot welds was investigated. Fig. 7 shows load-shortening diagrams for the frusta of angle $5^{\circ}$ of the same number of spot welds, but of different diameter. In Fig.8. the influence of the number of spot welds of the same diameter is presented. The results of the study indicate, that that the diameter and number of spot welds do not influence the crushing behavior of frusta significantly.

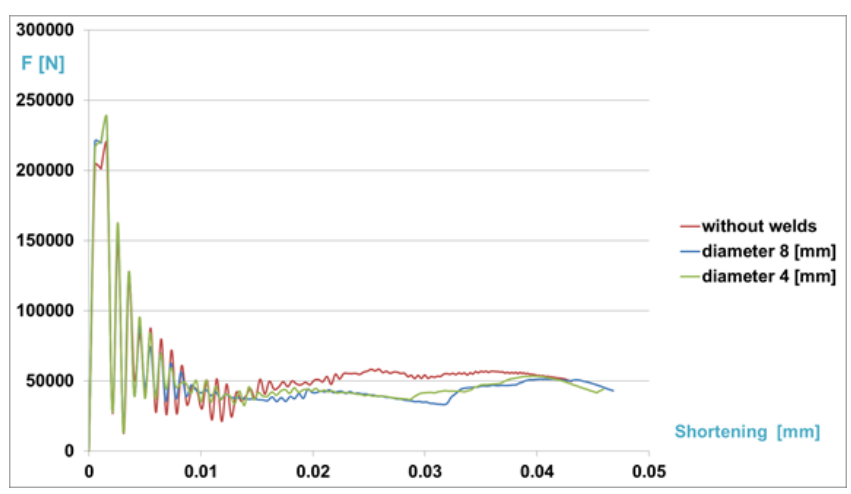

Fig. 7. Influence of spot weld diameter. Wall thickness $t=1 \mathrm{~mm}, \alpha=5^{\circ}$, spot weld diameter $d=8 \mathrm{~mm}, d=4 \mathrm{~mm}, n=8$

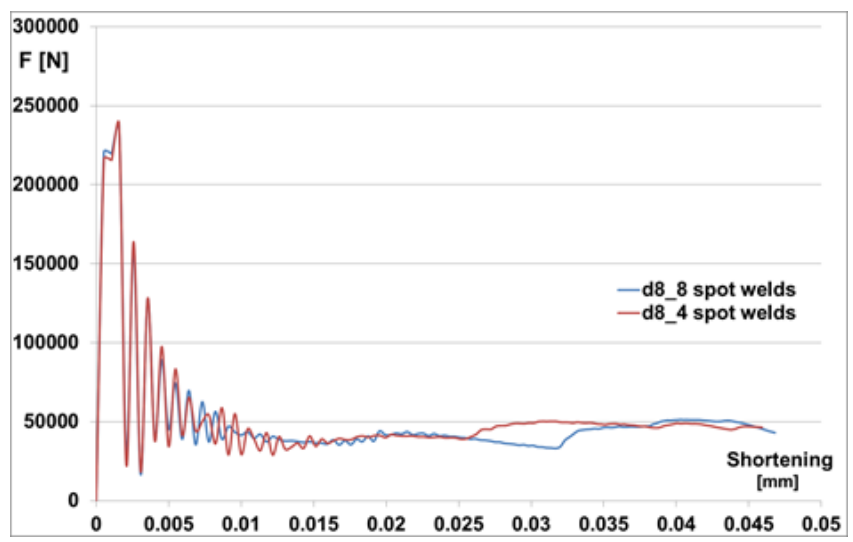

Fig. 8. Influence of spot weld diameter. Wall thickness $t=1 \mathrm{~mm}, \alpha=5^{\circ}$, spot weld diameter $d=8 \mathrm{~mm}, n=8$ and $n=4$

\subsection{Parametric study of energy absorption capability}

The parametric study was focused on the analysis into an optimal angle of frustum wall inclination (frustum angle) with respect to the energy absorbed, mean crusshing force (MCF) and crash load efficiency (CLF).

The subject of the parametric study was the frustum with 8 Spot welds of diameter $d=8 \mathrm{~mm}$. Frusta of different wall thickness were examined. 


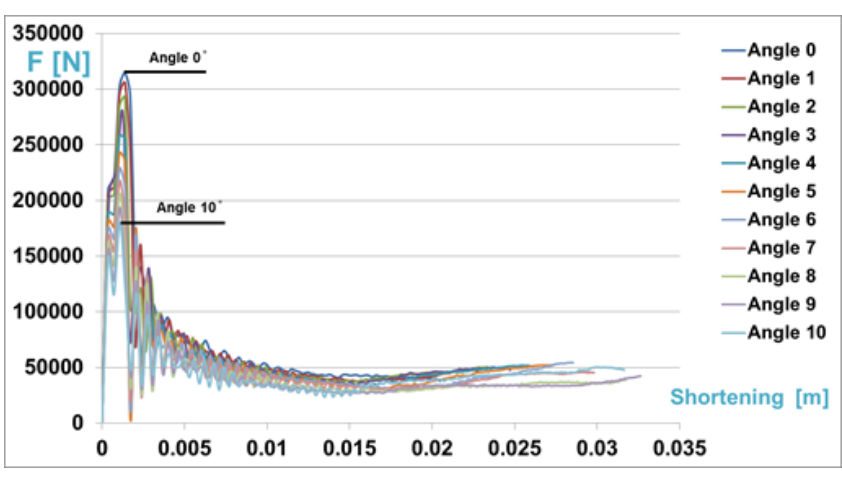

Fig. 9. Influence of frustum angle on the crushing behaviour; wall thickness $t=0.8 \mathrm{~mm}$

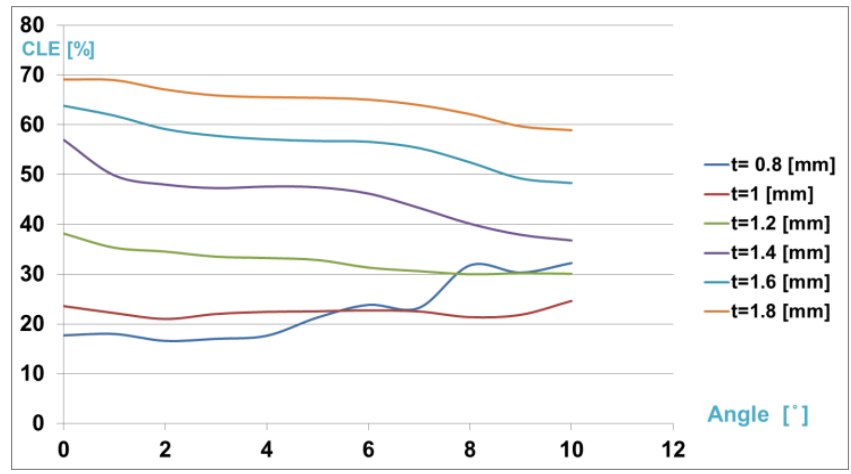

Fig. 10. Crash load effeciency (CLE)

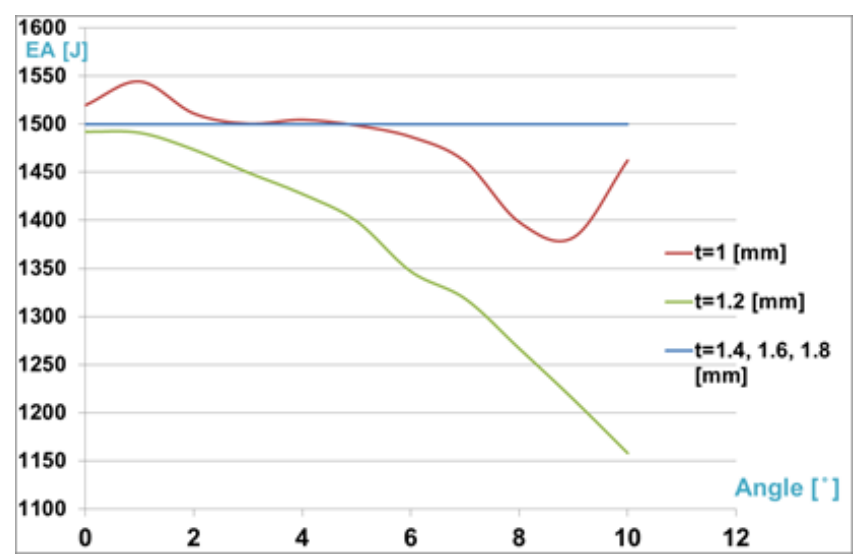

Fig. 11. Energy absorption (EA)

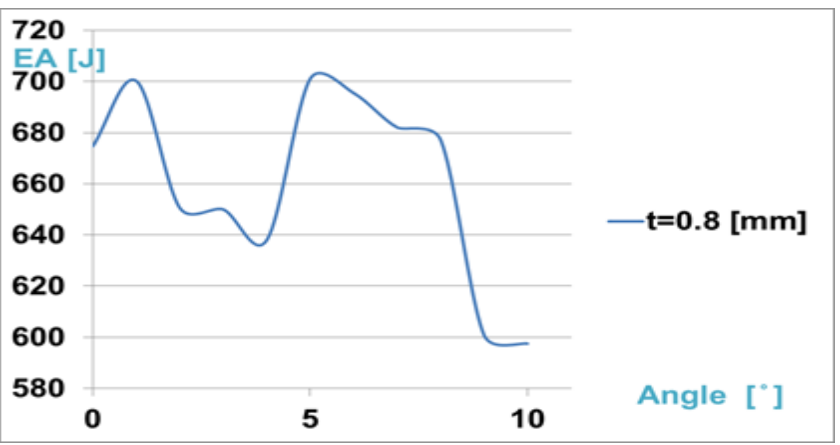

Fig. 12. Energy absorption (EA) for wall thickness $t=0.8 \mathrm{~mm}$

Fig. 9. shows load-shortening diagrams for the frustum of wall thickness $t=0.8 \mathrm{~mm}$ and for different frustum angles. The structural crushing behaviour is similar for all frustum angles. Howev- er, a significant decrease of peak crushing force with the increase of frustum angle is observed. In Fig. 10 CLE indicator in terms of frustum angle for different wall thickness values, which were examined, is presented. Fig.11 shows the energy absorption (EA) in terms of frustum angle for wall thickness values from $t=1$ to $t=1.8$. Similar diagram for one wall thickness $t=0.8 \mathrm{~mm}$ is presented in Fig.12. Fig.13. indicates the decrease of peak crushing force with the increase of frustum angle for wall thickness $t=0.8 \mathrm{~mm}$.

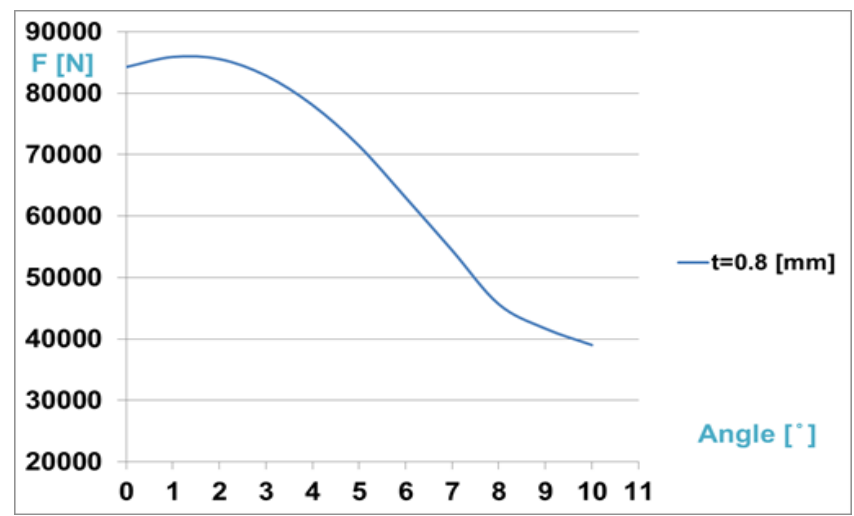

Fig. 13. Peak crushing force in terms of frustum angle for wall thickness $t=0.8 \mathrm{~mm}$

\section{FINAL REMARKS}

The results of the parametric study indicate significant decrease of peak crushing force with the increase of frustum angle (see Fig. 9 and 13).

The influence of frustum angle on the crashworthiness indicators are different for different wall thickness values. Relation of the energy absorption in terms of frustum angle is non-linear. For the lowest examined wall thickness $(t=0.8 \mathrm{~mm})$, there are two optimal values of the frustum angle $\left(\alpha=1^{\circ}\right.$ and $\left.\alpha=5^{\circ}\right)$, for which EA indicator is of maximum value. However, the increase of EA with respect to parallelepiped is not significant. For larger values of wall thickness the energy absorption is influenced by the frustum angle insignificantly. The ecception is wall thickness $t=1.2$ $\mathrm{nmm}$, for which EA indicator decreases significantly.

Crash load efficiency (CLE) increases with the increase of frustum angle for wall thicknes $t=0.8 \mathrm{~mm}$ only. For other examined values of wall thickness the influence is minor.

The presented results indicate, that research should be continued for wider range of geometric parameters. Thus, further parametric study is planned into multi-objective optimization of frusta under investigatuion, using response surface techniques.

\section{REFERENCES}

1. Abbasi M., Reddy S., Ghafari - Nazari A., Fard M. (2015), Multiobjective crashworthiness optimization of multi-cornered thinwalled sheet metal members, Thin-Walled Struct., 89, 31-41.

2. Alghamdi A.A.A. (2001), Collapsible impact energy absorbers: an overview, Thin-Walled Struct, 39, 189-213.

3. Dassault Systems (2013), Abaqus 6.13 Documentation, Abaqus Online Documentation.

4. Ferdynus M. (2013), An energy absorber in the form of a thin-walled column with square cross-section and dimples, Eksploatacja I Niezawodność Maintenance and Reliability, 15 (3), 253-258. 
5. Ferdynus M., Kotełko M. (2015), Dynamic axial crushing of flawed thin-walled square section tubes, Stability of Structures XIV Symposium, Departament of Strength of Materials, Lodz Univesity of Technology, 39-40.

6. Jones N. (2003) Structural Impact, Cambridge University Press.

7. Kaczyński P., Rusiński E. (2014), Strength estimation of joints in thin-walled Energy absorbing structures (in Polish), Oficyna Wydawnicza Politechniki Wrocławskiej.

8. Kotełko M., Mołdawa A., Jankowski M., (2014), Axial impact of open-section twcf columns experimental study, Romanian Journal of technical sciences - applied mechanics, former Revue Roumaine des sciences techniques, série de mécanique appliquée. (v. 59, No 1 -2, 2014); Special Issue "Stability and nonlinear analysis of steel structures - research advances", 59, 72-86.

9. Ali M., Ohioma E., Kraft F., Alam K. (2015) Theoretical, numerical, and experimental study of dynamic axial crushing of thin walled pentagon and cross-shape tubes, Thin-Walled Struct., 94, 253-272.

10. Reddy S., Abbasi M., Fard M. (2015), Multi-cornered thin-walled sheet metal members for enhanced crashworthiness and occupant protection, Thin-Walled Struct., 94, 56-66.
11. Rusiński E., et al., , (2004) Tests of thin-walled beams joined by spot welding, J. of Materials Processing Technology, 157-158, 405-409.

12. Sarkabiri B., Jahan A., Rezvani M. (2015), Multi-objective crashworthiness optimization of thin-walled conical groove tubes filled with polyurethane foam, 3 rd Polish Congress of Mechanics, 21 st International Conference o Computer Methods in Mechanics, 947-948.

13. Sharifi S., Shakeri M., Ebrahimi Fakhari H., Bodaghi M. (2015) Experimental investigation of bitubal circular energy absorbers under quasi-static axial load, Thin-Walled Struc., 89, 42-53.

The work has been presented over the XIVth Symposium of Stability of Structures, Zakopane, Poland in June 2015. 